\title{
Analysis of Char Prepared by Pyrolysis of Dabai (Canarium odontophyllum) Nutshells as a Potential Precursor of Biocarbon Used for Wastewater Treatment
}

\begin{abstract}
Ahmad Adzhar Bin Mohd Khairulzaim, ${ }^{\mathrm{a}}$ Md Rezaur Rahman, ${ }^{\mathrm{a}, *}$ Lidyana Roslan, ${ }^{\mathrm{a}}$ Muhammad Khusairy Bin Bakri, ${ }^{a}$ Afrasyab Khan, ${ }^{b}$ and Mohammed Mahbubul Matin ${ }^{\mathrm{c}}$

Dabai (Canarium odontophyllum) nutshells have considerable potential to be used as a viable precursor for biomass-based activated carbon. The material was carbonized at a temperature of $700^{\circ} \mathrm{C}$ for $2 \mathrm{~h}$, at a heating rate of $10{ }^{\circ} \mathrm{C} / \mathrm{min}$ under nitrogen gas flow. The char was analyzed the following ways: percentage of yield, percentage of ash content, Fourier transform infrared spectroscopy, scanning electron microscopy with energy dispersive x-ray analysis, and Brunauer, Emmett, and Teller surface area. The char had a maximum Brunauer, Emmett, and Teller surface area of $428 \mathrm{~m}^{2} / \mathrm{g}$ and the nitrogen adsorption-desorption isotherm of the char that was similar to a Type I adsorption isotherm, based on IUPAC classifications. The char also had a high carbon content (up to $93.6 \%)$ and a low ash content (3.67\%). Therefore, dabai nutshells were found to be a suitable lignocellulosic precursor for the synthesis of activated carbon.
\end{abstract}

Keywords: Canarium odontophyllum; Nutshell; Carbonization; Activated carbon; Adsorption

Contact information: a: Faculty of Engineering, Universiti Malaysia Sarawak, Jalan Datuk Mohammad Musa, Kota Samarahan, Sarawak 94300 Malaysia; b: Institute of Engineering and Technology, Department of Hydraulics and Hydraulic and Pneumatic Systems, South Ural State University, Lenin Prospect 76, Chelyabinsk 454080 Russian Federation; c: Bioorganic and Medicinal Chemistry Laboratory Faculty of Science, Department of Chemistry, University of Chittagong Bangladesh;

*Corresponding author: rmrezaur@unimas.my

\section{INTRODUCTION}

Water is a basic need for humans, as it is approximately $60 \%$ of total human weight. In addition, its losses through different metabolic and excretory cycles must be compensated by enough intake. Water may contain dangerous impurities, which can influence human health and the environment (Siong et al. 2014). Therefore, wastewater treatment plants play a crucial role in both safeguarding the sources of drinking water and providing an alternative production supply of water and treated wastewater. This requires an increased degree of water treatment depending on its uses. The monitoring and removal of trace pollutants are two of the biggest challenges of wastewater treatment plants (WWTPs). As such, WWTPs have created new adaptations in the form of the development of existing and new wastewater treatment systems, which reduce costs and maximize resources use (Campinas et al. 2016). Wastewater treatment utilizes filters and adsorbents for reducing the amount of pollutants or pollution levels in the discharge before being released into the environment. A similar approach is also applied to water supply treatment, before being channeled to domestic and industrial users.

Activated carbon (AC) is a material with various usages, ranging from quality 
adsorbents to semiconductors. The origins of activated carbon can be found in ancient Egypt (1500 BC), where the Egyptians utilized its adsorbent qualities for water cleansing and therapeutic purposes (Tadda et al. 2016). Activated carbon with a high carbon content can also be produced from environmental waste. Lignocellulosic and coal materials have been used as raw materials for the production of activated carbon. Physical activation and chemical activation are the two methods for processing activated carbon for water treatment processes. Chemical activation uses acidic or alkaline solution to induce changes on the surface of the materials, while physical activation used mechanical means to modify the surface topological structure. Due to its high surface area, microporous strength, and chemical complexity of its exterior area, activated carbon has a strong potential to adsorb heavy metal ions (Ahmad and Azam 2019).

A potential alternative to conventional charcoal as a precursor for activated carbon synthesis is lignocellulosic wastes. It is possible to consider the use of lignocellulosic biomass, as it is usually abundant in the form of agricultural waste. Environmental issues, e.g., agricultural waste accumulation, air pollution, and water pollution, could be addressed by turning those wastes into value-added goods, e.g., activated carbon. Moreover, the usage of lignocellulosic biomass activated carbon instead of fossil sources, i.e., coal, can reduce their impact on global warming. The carbon circulation between the atmosphere and the removal mechanism of contaminants is thus merely a carbon-neutral loop (Nor et al. 2013).

The morphology of activated carbon derived from the core and nut shells is influenced by phosphoric acid, according to Vicinisvarri et al. (2014). The findings revealed that rising phosphoric acid ( $80 \mathrm{wt} \%$ ) increased the velocity of cavity forming, resulting in the highest porosity surface in activated carbon. The vents on the outer surface of activated carbon vary, and the pore size is determined by the amount of carbonization and impregnation. The entire surface of the activated carbon in this situation is riddled with holes and odd shapes (Vicinisvarri et al. 2014; Yakout and El-Deen 2016). In an analysis of activated carbon output from olive stone using 60, 70, and 80\% w/w phosphoric acid, Yakout and El-Deen (2016) found that raising the acid concentration increased the surface area of the activated carbon. The activated carbon treated with $80 \%$ phosphoric acid had the largest surface area $\left(1218 \mathrm{~m}^{2} / \mathrm{g}\right)$ and pore volume $\left(0.63 \mathrm{~cm}^{3} / \mathrm{g}\right)$ of all the activated carbons tested (Yakout and El-Deen 2016). Yorgun and Yildiz (2015) confirmed that $\mathrm{H}_{3} \mathrm{PO}_{4}$ was an efficient activator agent, and they found that the pores formed on the surface of activated carbon are tunnel-shaped and have a honeycomb form using carbon electron micrograph scanning electron microscope photographs. As the corners of the cavities were distinctly apparent, the honeycomb holes of the activated carbon had completely formed (Yorgun and Yildiz 2015).

In general, lignocellulosic biomass specimens are comprised of three distinct components, i.e., cellulose, hemicelluloses, and lignin. Among the three, lignin is established as the major component responsible for the adsorption process in lignocellulosic biomass (Suhas et al. 2007). Lignocellulosic biomass is a good choice for use as a precursor to produce activated carbon, due to the rich carbon content of lignins (Demirbas 2004; Allen et al. 2005). In this research, the raw dabai nutshells were carbonized to obtain its biocarbon with different replication. Percentage of carbon yield and ash content were calculated and characterized by SEM-EDS, FTIR, and BET to determine the morphological, spectral, and porosity properties of the carbon. Through the properties obtained from the biocarbon from the dabai nutshell, it shows that the biocarbon has potential to be used as absorbent materials for wastewater treatment. 


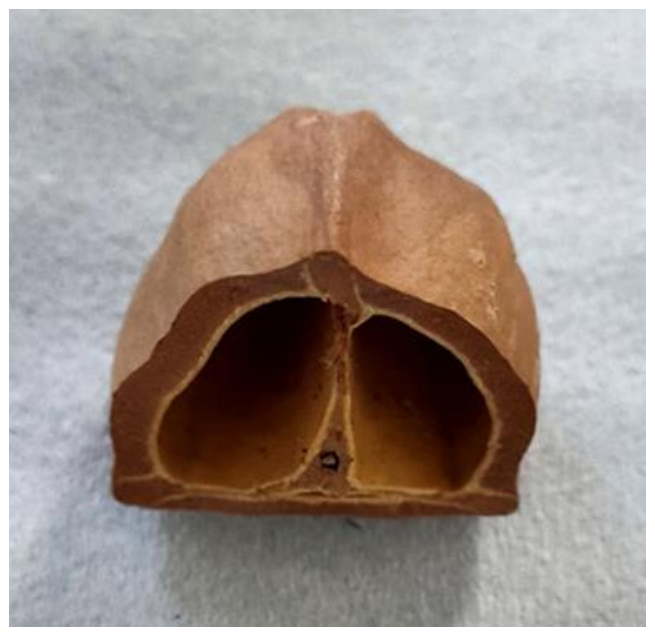

Fig. 1. Dabai nutshell

\section{Dabai Nutshells}

This study attempted to determine the properties of char synthesized from dabai nutshells, as a precursor for activated carbon. Figure 1 shows the dabai nutshell. Dabai (Canarium odontophyllum) is an indigenous seasonal fruit, which is found and famously known at Sibu and Kapit, Sarawak, on Borneo Island (Pin and Daniel 2016). According to Brooke and Yuon (2013), a young tree can yield $10 \mathrm{~kg}$ of dabai, while a mature tree (10 years or more) can yield 80 to $100 \mathrm{~kg}$. As a result, it was estimated that about 200,000 to $500,000 \mathrm{~kg}$ are produced each season. Inside the dabai nut is a seed coated with a rough and woody endocarp or shell. The physical features of this nutshell mimic the shell of a palm kernel (Vicinisvarri et al. 2014). Farmers usually have disposed the dabai nutshells via burning, which is viewed as a waste. In addition, this disposal method contributes to the release of carbon dioxide and other contaminants. In order to allow economic use of this agricultural by-product, it is proposed to use dabai nutshells as a raw material for the preparation of activated carbon (Vicinisvarri et al. 2014).

\section{EXPERIMENTAL}

\section{Materials}

The dabai fruits were purchased from a local market in Kuching, Sarawak, which were imported from Sibu, Sarawak.

\section{Preparation of the Nutshells}

The fruit was soaked in hot water for $20 \mathrm{~min}$. The nutshells were obtained by removing the flesh of the fruit from the nutshells. Then, the nutshells were cleaned using tap water before being dried using a convection oven (Convection Oven, IMPACT (UK), Model P12VSD) at a temperature of $45^{\circ} \mathrm{C}$ for $4 \mathrm{~h}$. It was uniformly spread on the plate for drying, and the convection fan was turned on to allow moisture to escape. The dried nutshells were crushed, and the inner nut was removed. To reduce the size of the nutshells, the nutshells were ground and sieved to the size less than $1 \mathrm{~mm}$. 


\section{Carbonization}

The carbonization of the precursor took place in a high temperature muffle furnace (Model KSL-1700X-A4, MTI CORPORATION (USA). Three crucibles (representing three identical replicates) were filled with $20 \mathrm{~g}$ of sieved nutshells. Then, the crucibles were closed using their respective lids before placing them into the furnace chamber. The carbonization took place at a temperature of $700{ }^{\circ} \mathrm{C}$ for $2 \mathrm{~h}$, at a heating rate of $10{ }^{\circ} \mathrm{C} / \mathrm{min}$ and under a nitrogen gas flow rate of $0.5 \mathrm{~L} / \mathrm{min}$ to avoid combustion in the furnace chamber. The char samples were kept in a desiccator until they reached room temperature. The final masses of the char samples were recorded to determine the percentage of yield. The temperature-time profile for the carbonization process is shown in Fig. 2.

\section{Analysis of the Char Samples}

The analysis of the char samples involved the percentage yield, which showed the amount of char that was synthesized from the carbonization and the amount of ash content (as a percentage) present in the char. The ash content percentage was determined by combusting $2 \mathrm{~g}$ of char at a temperature of $700{ }^{\circ} \mathrm{C}$ for $4 \mathrm{~h}$. Additional analysis of the char involved scanning electron microscopy with energy-dispersive $\mathrm{x}$-ray analysis (SEM-EDS) (Hitachi TM4000Plus tabletop microscope with a Quantax75 TM series energy dispersive X-ray spectrometer, Hitachi Ltd., Tokyo, Japan), Fourier transform infrared (FTIR) spectroscopy (IRAffinity ${ }^{-1}$ spectrophotometer, Shimadzu Corporation, Kyoto, Japan), and Brunauer-Emmett-Teller (BET) (Quantachrome Autosorb iQ, Quantachrome Instruments, Boynton Beach, FL, USA) surface area analysis. In addition, SEM-EDS and FTIR analysis was performed on the dabai nutshells.

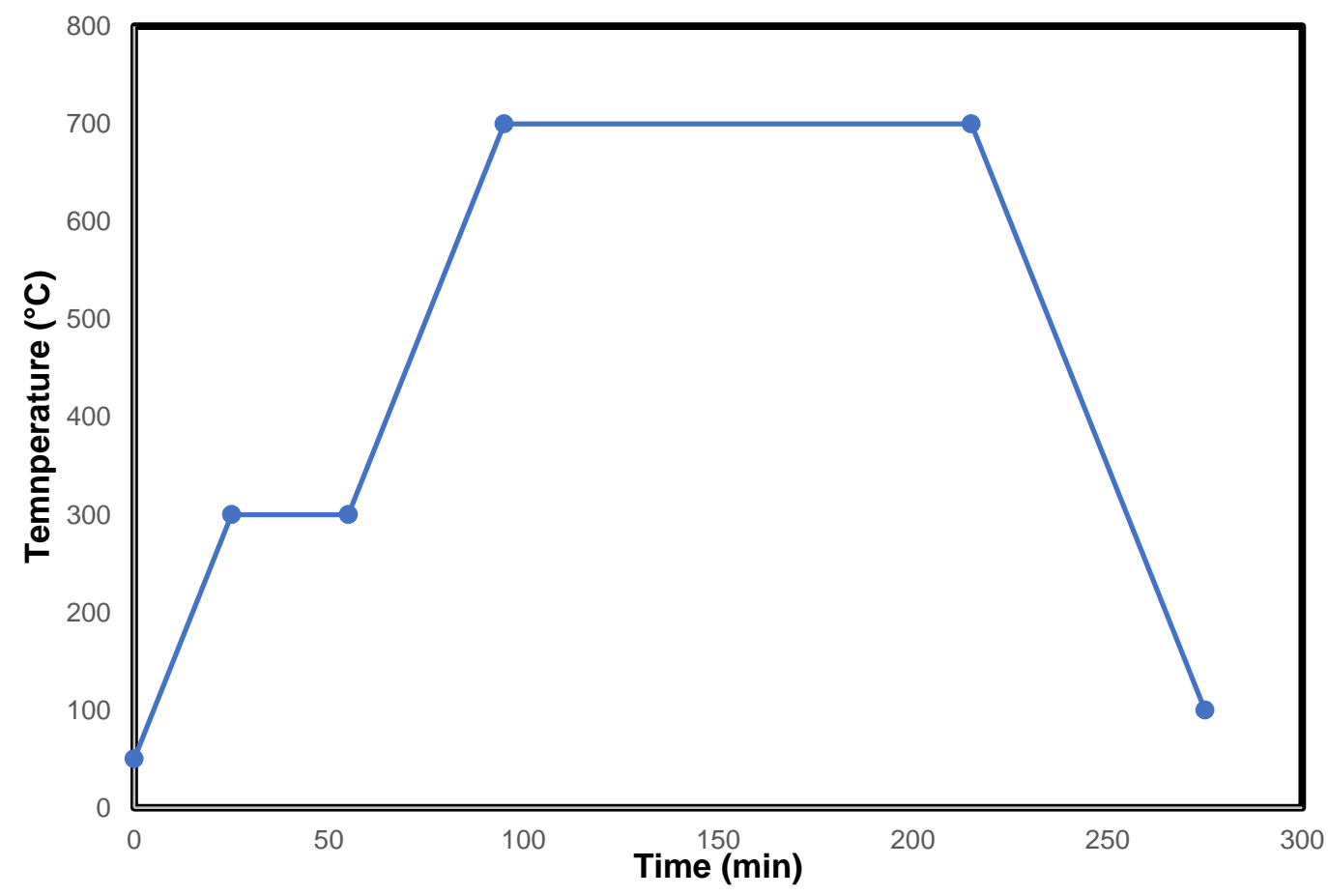

Fig. 2. Temperature-time profile for the carbonization 


\section{RESULTS AND DISCUSSION}

\section{Percentage Yield and Ash Content}

The percentage of yield from the carbonization of dabai nutshells under $\mathrm{N}_{2}$ gas is shown in Table 1 . The average yield amount was $26.5 \%$, which was comparable to other studies using agricultural biomass as the precursor for activated carbon (Ioannidou and Zabaniotou 2007). As shown in Table 2, the ash content analysis discovered that the average percentage of the amount of ash in the char after carbonization was 3.67\%. Based on the quality requirement of the activated carbon, this value was considered low enough, i.e., the ash content should be less than $10 \%$; this validated the suitability of dabai nutshells as a precursor for AC (Zulkania et al. 2018). The amount of ash was also lower compared to palm kernel-based AC (6.44\%) (Ademiluyi and David-West 2012). The presence of ash in the AC reduces the adsorption capability, which also reduces the mechanical strength of the carbon (Zulkania et al. 2018). Further leaching process are suggested to reduce the amount of ash in the char.

Table 1. Percentage Yield

\begin{tabular}{|c|c|c|c|}
\hline Replicate & Initial Mass $(\mathrm{g})$ & Final Mass $(\mathrm{g})$ & Percentage $(\%)$ \\
\hline 1 & 20.00 & 5.40 & 27.0 \\
\hline 2 & 20.00 & 5.28 & 26.4 \\
\hline 3 & 20.00 & 5.23 & 26.2 \\
\hline \multicolumn{3}{|c|}{ Average } \\
\hline
\end{tabular}

Table 2. Percentage of Ash Content in the Char Samples

\begin{tabular}{|c|c|c|c|c|c|c|}
\hline \multirow{2}{*}{ Replicate } & \multicolumn{5}{|c|}{ Mass (g) } & \multirow{2}{*}{$\begin{array}{c}\text { Ash Content } \\
\text { Percentage (\%) }\end{array}$} \\
\cline { 2 - 6 } & Crucible & $\begin{array}{c}\text { Crucible and } \\
\text { Sample }\end{array}$ & $\begin{array}{c}\text { Crucible and } \\
\text { Ash }\end{array}$ & Sample & Ash & \\
\hline 1 & 65.04 & 67.04 & 65.12 & 2.00 & 0.08 & 4.00 \\
\hline 2 & 67.40 & 69.40 & 67.48 & 2.00 & 0.08 & 4.00 \\
\hline 3 & 73.10 & 75.10 & 73.16 & 2.00 & 0.06 & 3.00 \\
\hline \multicolumn{7}{|c|}{ Average } \\
\hline
\end{tabular}

\section{Fourier Transform Infrared (FTIR) Spectral Properties}

Figure 3 shows the FTIR spectrum of dabai nutshells and the char derived from it. The spectra of dabai nutshells were similar to the spectra outlined in earlier research on the same material before it was activated with phosphoric acid (Vicinisvarri et al. 2014). Hydroxyl (-OH) stretching vibration was indicated by a broad band at a wavelength of $3348.4 \mathrm{~cm}^{-1}$. At a wavelength of $2920.2 \mathrm{~cm}^{-1}$, the peak band indicated $\mathrm{C}-\mathrm{H}$ stretching. A peak at a wavelength of $2166.1 \mathrm{~cm}^{-1}$ was attributed to thiocyanate stretching $(\mathrm{S}-\mathrm{C} \equiv \mathrm{N})$. The stretching of carbonyl groups $(\mathrm{C}=\mathrm{O})$ is represented by a peak at a wavelength of 1726.3 $\mathrm{cm}^{-1}$. The $\mathrm{C}=\mathrm{C}$ stretching of conjugate alkenes are represented by a shoulder peak at a wavelength of $1643.4 \mathrm{~cm}^{-1}$. An aromatic $\mathrm{C}=\mathrm{C}$ stretching band was observed at a wavelength of $1514.1 \mathrm{~cm}^{-1}$; at a wavelength of $1643.4 \mathrm{~cm}^{-1}$, an aromatic $\mathrm{C}=\mathrm{O}$ stretching band was shown. The strong peak at a wavelength of $1033.8 \mathrm{~cm}^{-1}$ indicated C-O-C stretching. A small peak at a wavelength of $1238.3 \mathrm{~cm}^{-1}$ represented C-O stretching (Law et al. 2020, 2021). 
After carbonization, the spectra of the char indicated a decline in peak intensity, which potentially hinted at a major loss of functional groups in the material. Weak bands in the spectra of the replicates at a wavelength range of $1000 \mathrm{~cm}^{-1}$ to $1200 \mathrm{~cm}^{-1}$ possibly represented $\mathrm{C}-\mathrm{O}$ stretching.

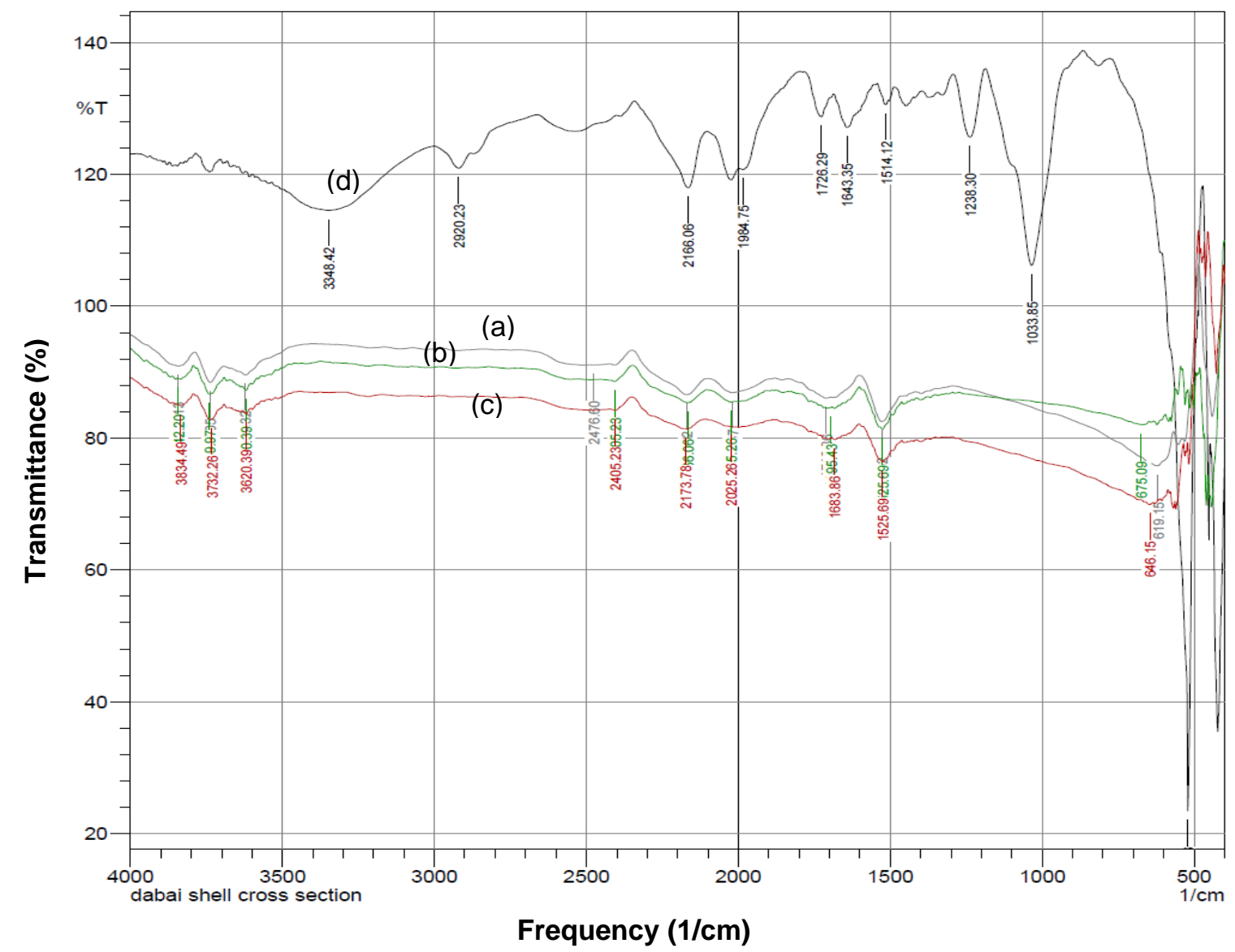

Fig. 3. The FTIR spectra for dabai char: (a) Replicate 1 (Grey); (b) Replicate 2 (Green); Replicate 3 (red); and (d) raw dabai nutshell (Black)

\section{Morphological Properties}

Figures 4a, 4b, and 4c show the SEM images of the char replicates, and Fig. 4d shows the raw dabai nutshells at $1000 \times$ magnification. The dabai nutshell image shows that there was no presence of pores on the surface of the material. The structure was observed as rigid and packed, which is typical for lignocellulosic material. After carbonization, a porous structure started to form on the material, but was uneven and random in size. The presence of the white structure on the char indicated the presence of ash, as confirmed through SEM-EDS. 


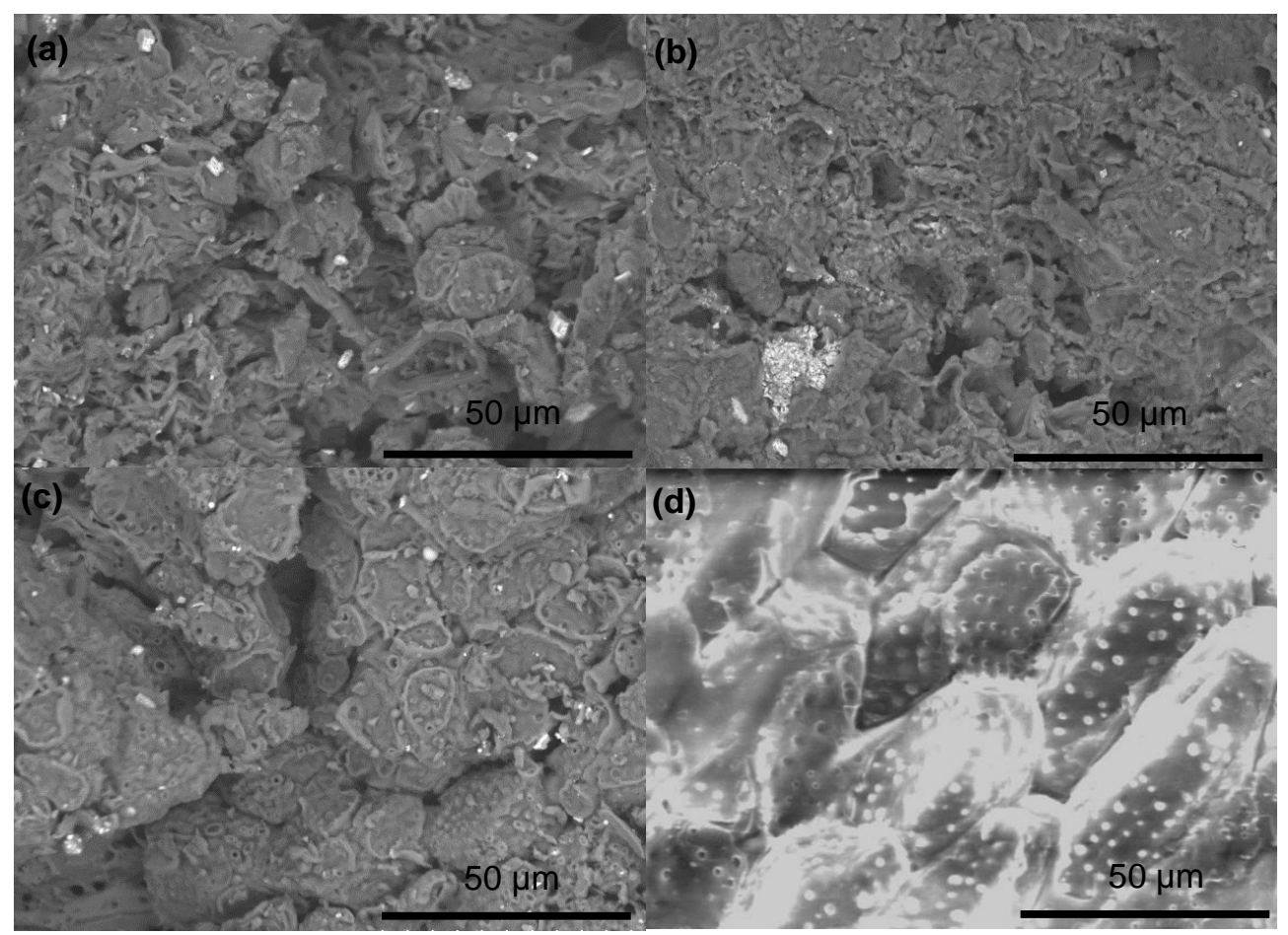

Fig. 4. SEM figures for dabai char: (a): Replicate 1; (b) Replicate 2; (c) Replicate 3; and (d) raw dabai nutshell

\section{Element Properties}

Figure 5 and Table 3 shows the SEM-EDS spectrum of the dabai nutshell, which was predominated by carbon and oxygen, with low amounts of calcium and potassium. After carbonization, the amount of oxygen in the char was reduced to $5 \%$ to $8 \%$, while the percentage of carbon increased from $55.5 \%$ to $86.5 \%$ to $93.6 \%$ (as shown in Figs. 6, 7, and 8 ). The presence of other elements was negligible, as their percentage was extremely low.

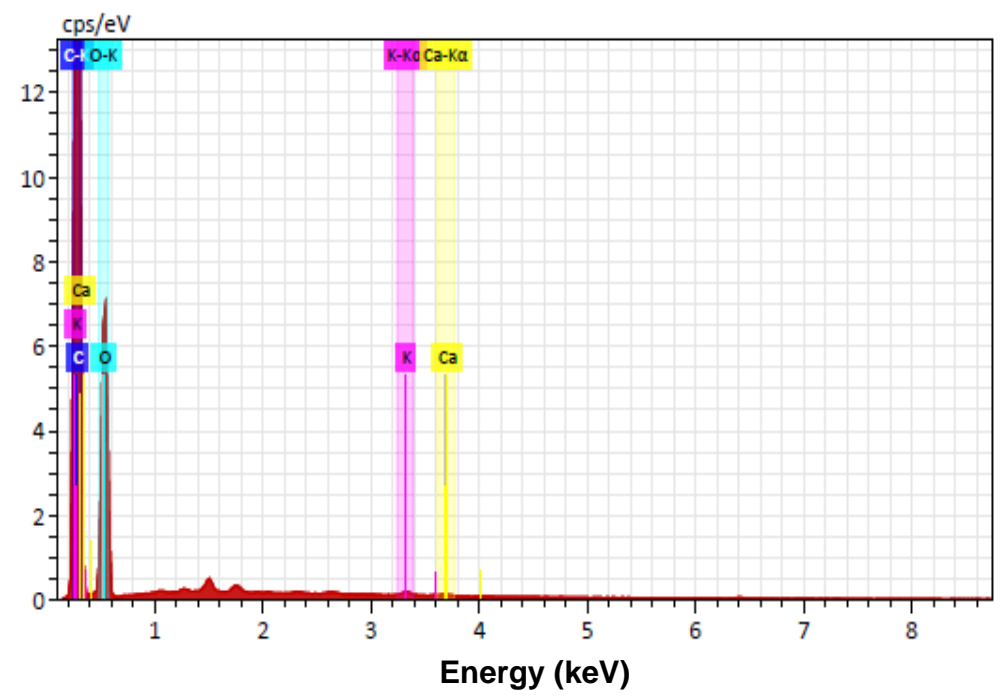

Fig. 5. EDS spectrum for raw dabai nutshell 


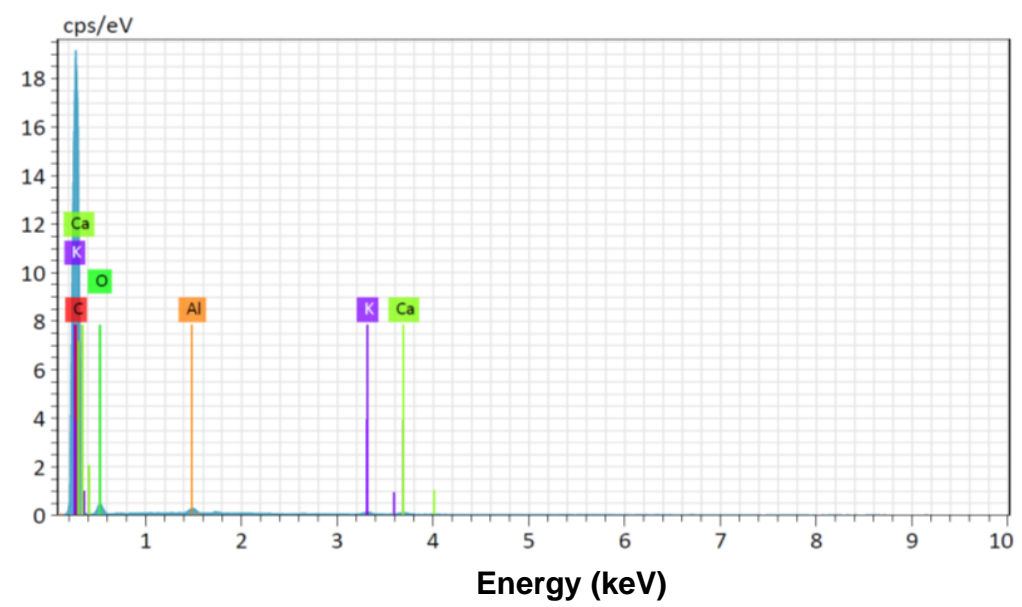

Fig. 6. EDS spectrum for dabai char replicate 1

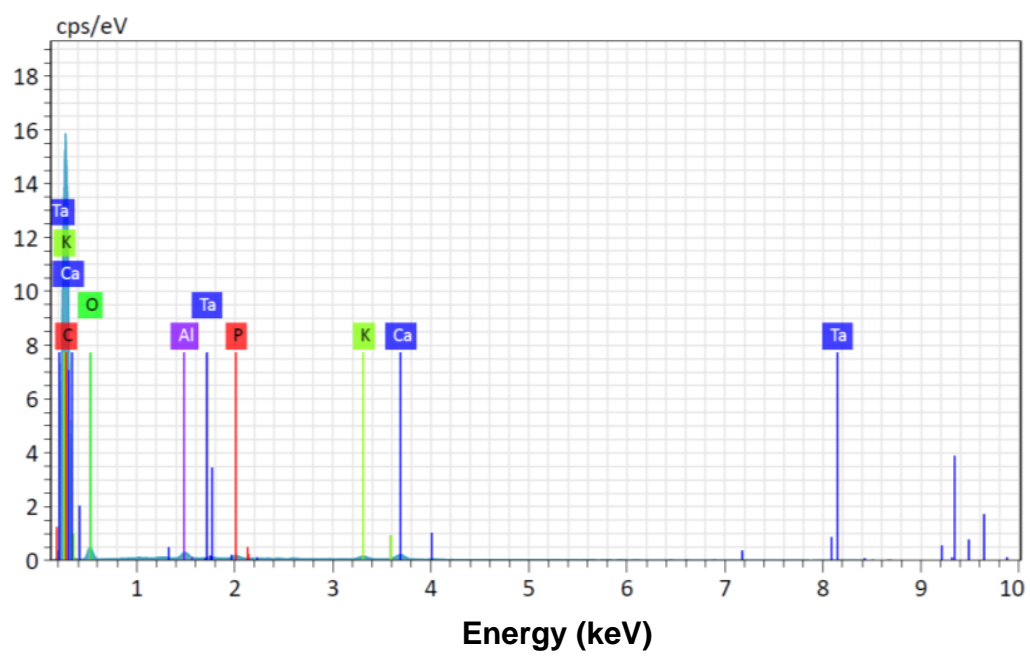

Fig. 7. EDS spectrum for dabai char replicate 2

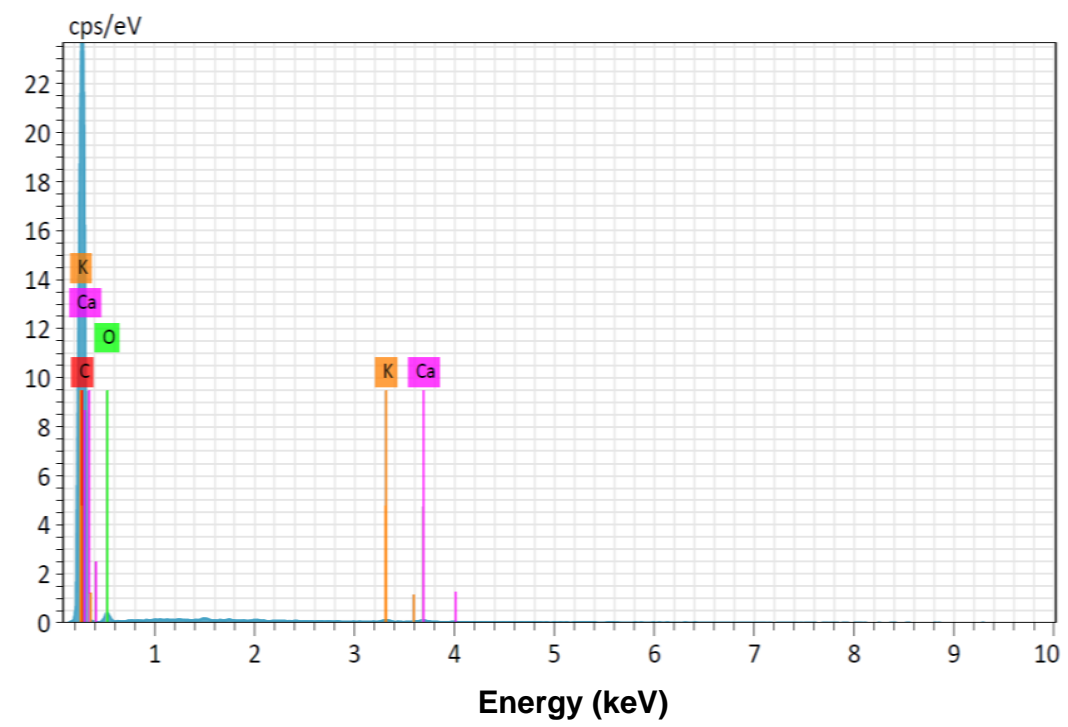

Fig. 8. EDS spectrum for dabai char replicate 3 
Table 3. Mass Percentage of Elements in Dabai Char Based on EDS Analysis

\begin{tabular}{|c|c|c|c|c|}
\hline \multirow{2}{*}{ Element } & \multicolumn{4}{|c|}{ Mass Percentage (\%) } \\
\cline { 2 - 5 } & Nutshell (Before Carbonization) & Replicate 1 & Replicate 2 & Replicate 3 \\
\hline $\mathrm{C}$ & 55.54 & 90.43 & 86.52 & 93.57 \\
\hline $\mathrm{O}$ & 44.29 & 6.95 & 7.70 & 5.04 \\
\hline $\mathrm{Ca}$ & 0.08 & 1.01 & 2.98 & 0.80 \\
\hline $\mathrm{K}$ & 0.20 & 0.85 & 1.28 & 0.58 \\
\hline $\mathrm{Al}$ & - & 0.77 & 0.78 & - \\
\hline $\mathrm{P}$ & & - & 0.58 & - \\
\hline $\mathrm{T}$ & & - & 0.16 & - \\
\hline Total & 100.0000 & 100.00 & 100.00 & 100.00 \\
\hline
\end{tabular}

\section{Porosity Properties}

Figure 9 shows the nitrogen gas adsorption-desorption isotherms of the dabai char. All three char replicates were found to have higher $\mathrm{N}_{2}$ adsorption as the relative pressure increased. The isotherms were similar to Type I adsorption isotherms, based on IUPAC classifications, whereas the isotherms represented low $\mathrm{N}_{2}$ adsorption at low relative pressures, with a slightly increasing adsorption as the relative pressure increased (Kecili and Hussain 2018). A study by Vicinisvarri et al. (2014) demonstrated that chemical activation helped to increase nitrogen adsorption, up to $310 \mathrm{~cm}^{3} / \mathrm{g}$. Table 7 tabulated the BET surface area and the average pore radius of the char. The BET surface area obtained was comparable to other activated carbon samples synthesized from agricultural residues (Ioannidou and Zabaniotou 2007). For the average pore radius, the radii of the char was in the smaller range (10.3 $\AA$ to $11.1 \AA$ ) compared to the phosphoric acid-activated carbon from the same precursor (18.71 $\AA$ to $23.14 \AA$ ).

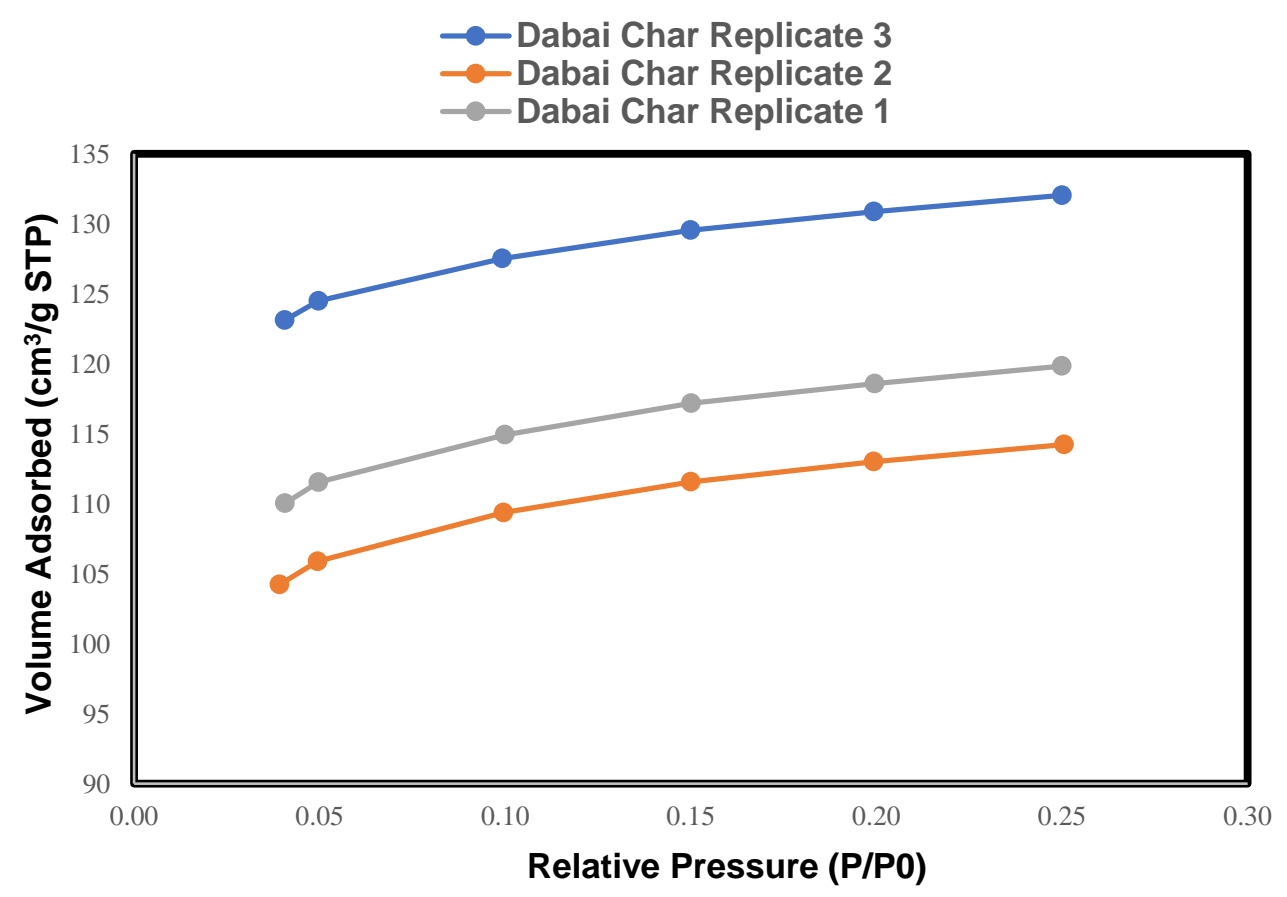

Fig. 9. Nitrogen gas adsorption-desorption isotherms 
Table 4. BET Surface Areas of the Dabai Char Replicates

\begin{tabular}{|c|c|c|}
\hline Replicate & BET Surface Area $\left(\mathrm{m}^{2} / \mathrm{g}\right)$ & Average Pore Radius $(\AA)$ \\
\hline 1 & 389 & 11.1 \\
\hline 2 & 371 & 10.6 \\
\hline 3 & 428 & 10.3 \\
\hline
\end{tabular}

\section{CONCLUSIONS}

Several property tests were performed on the char synthesized from dabai nutshells. The results indicated that the material had a high percentage of carbon (up to 93.6\%). It also had a comparable percentage yield (up to $26.5 \%$ ), low ash content $(3.67 \%$ ), and comparable BET surface area to several different activated carbon samples produced from lignocellulosic materials. This showed that dabai has a huge potential, especially its nutshell, which was used as the precursor for a carbon-based adsorbent.

\section{ACKNOWLEDGMENTS}

This research was performed with funding from the Ministry of Education Malaysia, with Research Grant no. JPT S(BPKI)2000/09/01/106(33) (UNIMAS No. grant F02/RACER/1854/2019). The authors wish to acknowledge the Faculty of Engineering at the Universiti Malaysia Sarawak (UNIMAS) for their lab facilities support.

\section{REFERENCES CITED}

Ademiluyi, F. T., and David-West, E. O. (2012). "Effect of chemical activation on the adsorption of heavy metals using activated carbons from waste materials," ISRN Chemical Engineering 2012, 1-5. DOI: 10.5402/2012/674209

Ahmad, A., and Azam, T. (2019). "Water purification technologies," in: Bottled and Packaged Water Volume 4: The Science of Beverages, A. M. Grumezescu and A. M. Holban (ed.), Woodhead Publishing, Sawston, United Kingdom.

Allen, S. J., Koumanova, B., Kircheva, Z., and Nenkova, S. (2005). "Adsorption of 2nitrophenol by technical hydrolysis lignin: Kinetics, mass transfer, and equilibrium studies," Industrial and Engineering Chemistry Research 44(7), 2281-2287. DOI: 10.1021/ie049455d

Brooke, P., and Yuon, L. C. (2013). "Dabai planting material and propagation technique," Jabatan Pertanian Sarawak. Viewed at http://myagric.upm.edu.my/id/eprint/12092/

Campinas, M., Mesquita, E., Viegas, R. M. C., and Rosa, M. (2016). "Using activated carbon based technologies for the removal of emerging contaminants from water/wastewater," Boletín del Grupo Español del Carbón 40, 13-17.

Demirbas, A. (2004). "Adsorption of lead and cadmium ions in aqueous solutions onto modified lignin from alkali glycerol delignication," Journal of Hazardous Materials 109(1-3), 221-226. DOI: 10.1016/j.jhazmat.2004.04.002

Ioannidou, O., and Zabaniotou, A. (2007). "Agricultural residues as precursors for 
activated carbon production - A review," Renewable and Sustainable Energy Reviews 11(9), 1966-2005. DOI: 10.1016/j.rser.2006.03.013

Kecili, R., and Hussain, C. M. (2018). "Mechanism of adsorption on nanomaterials," in: Nanomaterials in Chromatography: Current Trends in Chromatographic Research Technology and Techniques, C. M. Hussain (ed.), Elsevier, Amsterdam, Netherlands.

Law, P. N. K., Rahman, M. R., Hamdan, S., Jayamani, E., Bakri, M. K. B., and Sanaullah, K. (2020). "Synthesis and characterization of micro-nano carbon filler from jatropha seeds," BioResources 15(2), 3237-3251. DOI:

10.15376/biores.15.2.3237-3251

Law, P. N. K., Rahman, M. R., Ahmed, A. A., Kuok, K. K., Bakri, M. K. B., Tazeddinova, D., Kazhmukanbetkyzy, Z. A., and Torebek, B. (2021). "Morphological and thermal properties of composites prepared with poly(lactic acid), poly(ethylenealt-maleic anhydride), and biochar from microwave-pyrolyzed jatropha seeds," BioResources 16(2), 3171-3185. DOI: 10.15376/biores.16.2.3171-3185

Nor, N. M., Lau, L. C., Lee, K. T., and Mohamed, A. R. (2013). "Synthesis of activated carbon from lignocellulosic biomass and its applications in air pollution control - A review," Journal of Environmental Chemical Engineering 1(4), 658-666. DOI: 10.1016/j.jece.2013.09.017

Pin, C. H., and Daniel, N. (2016). Dabai, specialty fruit in Sarawak," (https://blogmardi.wordpress.com/2017/02/13/dabai-specialty-fruit-of-sarawak/), Access April 12, 2021.

Siong, Y. K., Idris, J., and Atabaki, M. (2014). "Performance of activated carbon in water filters," Water Resources 2014, 1-19.

Suhas, Carrott, P. J. M., and Ribeiro Carrott, M. M. L. (2007). "Lignin - From natural adsorbent to activated carbon: A review," Bioresource Technology 98(12), 23012312.DOI: 10.1016/j.biortech.2006.08.008

Tadda, M. A., Ahsan, A., Shitu, A., ElSergany, M., Arunkumar, T., Jose, B., Razzaque, M. A., and Daud, N. N. N. (2016). "A review on activated carbon: Process, application and prospects," Journal of Advanced Civil Engineering Practice and Research 2(1), 7-13.

Vicinisvarri, I., Kumar, S. S., Aimi, A. W. N., Norain, I., and Izza, H. N. (2014). "Preparation and characterization of phosphoric acid activated carbon from Canarium odontophyllum (Dabai) nutshell for methylene blue adsorption," Research Journal of Chemistry and Environment 18(2), 57-62.

Yakout, S. M., and El-Deen, G. S. (2016). "Characterization of activated carbon prepared by phosphoric acid activation of olive stones," Arabian Journal of Chemistry 9(2), S1155-S1162. DOI: 10.1016/j.arabjc.2011.12.002

Yorgun, S., and Yildiz, D. (2015). "Preparation and characterization of activated carbons from Paulownia wood by chemical activation with $\mathrm{H}_{3} \mathrm{PO}_{4}$," Journal of the Taiwan Institute of Chemical Engineers 53(1), 122-131. DOI: 10.1016/j.jtice.2015.02.032

Zulkania, A., Hanum, G. F., and Rezki, A. S. (2018). "The potential of activated carbon derived from bio-char waste of bio-oil pyrolysis as adsorbent," in: Proceedings of the $2^{\text {nd }}$ International Conference on Engineering and Technology for Sustainable Development, 13-14 September, Yogyakarta, Indonesia, pp. 1-6.

Article submitted: March 21, 2021; Peer review completed: May 9, 2021; Revised version received: May 11, 2021; Accepted: May 13, 2021; Published: May 26, 2021. DOI: 10.15376/biores.16.3.5036-5046 